УДК 376.3

\title{
Особенности ценностного отношения к семье как фактор трансформаций ценностно-смысло- вой сферы у младших школьников с дисграфией и дислексией в условиях цифрового общества
}

\author{
Едена А. Мацюк \\ Российская Федерация \\ E-mail: elenamacjuk@yandex.ru \\ ORCID: https://orcid.org/0000-0002-8575-5845
}

Донской государственный технический университет, г. Ростов-на-Дону,

\section{Париса П. Агафонова}

МАОУ «Дицей № 27 им. А. В. Суворова», г. Ростов-на-Дону, Российская Федерация

\section{Елена Ю. Смертина}

МАОУ «Дицей № 27 им. А. В. Суворова», г. Ростов-на-Дону, Российская Федерация

\section{Аннотация}

В статье рассматриваются вопросы влияния нарушений процессов письма и чтения у м^аАших Школьников на орормирование ценностного отношения к семье как параметра развития смысловой сферы личности у этой категории обучающихся. Научная новизна состоит в проведении сравнительного анализа характеристик ценностно- смысловой сореры у учащихся 8-10 ^ет с Аисграфией, Аислексией и их сверстников без речевых расстройств. Во Ввелении рассматриваются особенности фрормирования ориентаций на семейные ценности у обучающихся 8-10 ^ет с Аисграфрией и Аислексией, представляющих широкую категорию среди учеников общеобразовательных школ в связи с внеАрением программ инкАюзивного образования и процесса цифровизации современного общества. В разделе Методы описаны процедура Аиагностики состояния устно- речевой и письменно-речевой Аеятельности посреАством ^огопеАических методов и психометрического эксперимента: оценка уровня сорормированности процессов чтения и письма по среАствам методики Т. А. Фотековой, Т. В. Ахутиной и характеристик межличностных отношений в семье при выполнении проективного теста «Рисунок семьи». В разделе Результаты представлены результаты эмпирического исслеАОвания. Полностью поАтвердилось предположение о наличии специфиики характеристик межличностного отношения в семье у млалших школьников с Аисграфрией и Аислексией, наиболее выраженных по категориям тревожность, конфрликтность, вражАебность, чувство 
неполноценности в семье. В разделе Обсужление результатов полученные Аанные были сравнены с результатами исслеАований о взаимосвязи психологических особенностей млаАших школьников с Аисграфией и Аислексией и специфики характеристик ценностного отношения к семье у этой категории Аетей. В Выводах Аелается заключение о том, что результаты исслеАования особенностей межличностных отношений в семье млаАших школьников с Аисграфрией и Аислексией позволяют описать трансфоомации смысловой сореры таких учеников и Аать практические рекомендации по гармонизации развития и оптимизации обучения этой категории школьников.

\section{КАючевые слова}

семейные ценности, ценностно-смысловая сорера, Аисграсфия, дислексия, млалшие школьники

\section{Для цитирования}

Мацюк Е. А., Агафонова А. П., Смертина Е. Ю. Особенности ценностного отношения к семье как фактор трансформаций ценностно-смысловой сферы у младших школьников с дисграфией и дислексией в условиях цифрового общества // Инновационная наука: психология, педагогика, дефектология. 2021. Т. 4, No 5. C. 6-22. doi: https://doi. org/10.23947/2658-7165-2021-4-5-6-22

\section{Special aspects of the values-based attitude towards the family as a factor in the transformations of the value-meaning sphere in elementary school children with dysgraphia and dyslexia within the conditions of digital society}

\section{Elena A. Matsyuk}

Don State Technical University, Rostov-on-Don, Russian Federation

E-mail: elenamacjuk@yandex.ru

ORCID: https://orcid.org/0000-0002-8575-5845

Larisa P. Agafonova

MAOU "Lyceum No. 27 named after. A. V. Suvorov", Rostov-on-Don, Russian Federation

Elena Y. Smertina

MAOU "Lyceum No. 27 named after. A. V. Suvorov", Rostov-on-Don, Russian Federation 
КОРРЕКЦИОННАЯ ПЕДАГОГИКА

\begin{abstract}
This article considers the questions of writing and reading disorders of elementary school children influence a values-based attitude formation towards the family as a parameter of the personality meaning sphere developmental growth in this category of students. The scientific novelty lies in the comparative analysis of the value-meaning sphere characteristics in 8-10 aged students with dysgraphia, dyslexia, and peers without speech disorders. The Introduction examines the special aspects of the formation of the orientations towards family values in students aged 8-10 years with dysgraphia and dyslexia. They account for a wide category among students of general education schools in connection with the advent of inclusive education programs and the digitalization of modern society. The Methods section describes the procedure for diagnosing the state of verbal-speech and writing-speech activity using speech therapy methods and a psychometric experiment: an appraisal of the level of formation of the processes of reading and writing using the methods by Fotekova T. A., and Akhutina T. V. and the characteristics of interpersonal relations in the family when performing the projective test "Family drawing". The Results section describes the findings of the empirical research. The assumption about the presence of specific characteristics of the interpersonal relations in the family in elementary school children with dysgraphia and dyslexia was fully confirmed. They were most pronounced in the following categories: anxiety, proneness to conflict, hostility, feelings of inferiority in the family. The Discussion of results section describes the comparison of the obtained data with the results of other studies. These studies examined the relationship between the psychological characteristics of elementary school children with dysgraphia and dyslexia and the specifics of the characteristics of the value-based attitude towards the family in this category of children. The Conclusions section shows that the results of the study of the special aspects of interpersonal relations in the family of elementary school children with dysgraphia and dyslexia make it possible to describe the transformations of the meaning sphere of such students. This also makes it possible to give practical recommendations for the harmonization of development, and optimization of education for this category of school children.
\end{abstract}

\title{
Keywords
}

family values, value-meaning sphere, dysgraphia, dyslexia, elementary school children

\section{For citation}

Matsyuk E. A., Agafonova L. P., Smertina E. Yu. Special aspects of the values-based attitude towards the family as a factor in the transformations of the value-meaning sphere in elementary school children with dysgraphia and dyslexia within the conditions of digital society, 4(5), 6-22. doi: https://doi. org/10.23947/2658-7165-2021-4-5-6-22 


\section{Введение}

Система ценностей, которыми обладает человек, служит интегральной характеристикой, задающей вектор развития индивидуально- психологических особенностей дичности, формирующей её устойчивость и целостность. Важнейшей ценностью в жизни человека, по мнению ряда исследователей, является семья, а междичностное взаимодействие в семье, как первичной малой группе общества в целом, значительно вдияет на формирование структуры дичности (Грязнов, 2020; Ефимова, Девых, 2020).

Поколение современных молодых родителей, воспитывающих детей младшего школьного возраста, выступает новой моделью дичности, сформировавшейся в эпоху атрибутов информационного общества и внутриличностные конструкты людей этого поколения (ценности, интересы, мировоззрение) образовались, в том числе, под вдиянием цифровых технологий. Однако нет данных, свидетельствующих об отсутствии традиционных семейных ценностей в системе ценностных установок молодых родителей, адаптированной к изменившимся условиям. Напротив, по мнению социолога Рональда Инглхарта, между социоэкономическим окружением и ценностными приоритетами нет отношений непосредственного регулирования и базовые ценности дичности отражают условия, доминировавшие в, так называемые, «формативные годы»-предшествовавшие периоду зрелости (Inglehart, 2018). Этот вывод подтверждается результатами опросов, проведённых в последние годы в нашей стране, показавших, что большинство молодых дюдей в возрасте от 15 до 29 лет сочди семью, любовь, образование, свободу и дружбу -наиболее важными ценностями, а 60 \% респондентов указали семью и воспитание как источники ценностей для человечества (Фактор, Камолов, Никандрова, 2018). Вместе с тем, была обнаружена недостаточная сформированность самих представлений современной молодёжи о семейных ценностях: духовные и всеобъемлющие ценности зачастую подменяются категориями «витального чувства» (Мурзина, 2018). Есть мнение, что в современном социуме демократического общества, рассматриваемом как общество знаний с преобладанием людей, привыкших думать самостоятельно, основную ценность имеет общественная модель самовыражения (Inglehart, 2018). Такая среда развития вдияет на характеристики ценностно- смысловой сферы современных детей.

Развитие ценностного отношения к семье, по мнению ряда исследователей (Д. И. Божович, Л. С. Выготский, А. Н. Леонтьев, А. В. Запорожец, В. Н. Мясищев) закладывается именно в младшем школьном возрасте, от условно - рефлекторного уровня, характеризующегося первичными положительными или отрицательными реакциями на раздражители, до собственно-духовного уровня, когда общественные и семейные законы и традиции превращаются во внутреннее регуяятивное поведение. Начиная с эмоционального восприятия ситуации 
КОРРЕКЦИОННАЯ ПЕДАГОГИКА

в семье, постепенно ребёнок осознаёт свою сопричастность к ней и на последнем этапе соотносит ценность семьи с другими значимыми для него ценностями,подчеркивал В. А. Ядов (Ядов, 2013). Интенцию этому развитию, по мнению Н. Е. Щурковой, даёт устойчивая связь ребёнка как субъекта общения, с семьёй как объектом окружающего мира, выступающая в социальном значении (Щуркова, 2002). Таким образом, формирование ценностного отношения к семье затрагивает осознание и проработку глубинных дичностных смыслов, в результате которой ребёнку, по мере накопления жизненного опыта, предстоит выработать для себя личностные ценности, содержащие в себе смысловое, эмоционально переживаемое отношение к жизни.

Согласно теории Б. С. Братуся, способность личности ценностно относить себя к миру людей, и миру в целом, и является первым результатом формирования у личности ценностно- смысловой сферы (Братусь, 1999). С одной стороны, дети младшего школьного возраста наиболее подвержены восприятию и отражению мнения взрослых, вдияющего на их личностные качества, убеждения, смысловую сферу, востребованность в обществе, но с другой, оказавшись в новой социальной роли, связанной с положением школьника, попадают в более сложную, в содержательном плане, систему отношений со сверстниками и взрослыми, повышается уровень осознанности последствий своих действий и действий окружающих, возникают интенции развития прогностической функции,-подчёркивают исследователи (Kuznetcova, Akhmetzyanova, Nigmatullina, Kurbanova, 2017). В период начального школьного обучения перестраиваются и детско-родительские отношения в связи с тем, что у ребёнка появдяются новые обязанности, со стороны родителей к нему предъявдяются новые требования.

Противоречивость системы ценностей, сформированной у родителей и учителей, отсутствие единой концепции воспитания, недостаточное внимание к проблемам становления ценностных отношений, ориентированность на знания как на основной результат образования, создают значительные трудности в становлении ценностных отношений у младших школьников. Гармонизация выстраивания собственной системы ценностей у детей возможна только при организованном взаимодействие семьи и школы, инициатором которого должна выступать школа как структура, обладающая большими педагогическими возможностями, понимающая необходимость и значимость такой работы, умеющая расположить к себе родителей и правильно психологически их настроить.

Однако беспрецедентные вызовы, встающие перед системой образования, связанные с цивилизационными процессами и возросшей частотой возникновения ситуаций неопределённости в обществе, таких как пандемия Covid-19, вызывают динамичные трансформации образовательного пространства, уже находящегося в процессе реформации под вдиянием инновационных процессов и идей гуманизации. Процессы динамичных изменений социальной жизни детей 
и подростков в связи с ограничениями живого общения, увеличением массовой доли цифровых форматов в организации обучения, накладываются на поэтапное внедрение инклюзивных форм образования в России. «Современная школа становится институтом формирования новых ценностей: детей готовят к партнёрскому, доброжелательному отношению к детям, имеющим разные образовательные потребности»,- указывают И. В. Абакумова и соавторы (Абакумова, Ермаков, Косикова, 2016, с. 30). Автор разработок дифференцированных образовательных стандартов для детей с речевыми расстройствами Г. В. Чиркина, предложила использование понятия «особые образовательные потребности» в отношении способностей к обучению детей с проблемами в развитии (Чиркина, 2012). Учёный подчёркивала, что включение в систему общего образования детей, имеющих определённые особенности развития, требует учёта не только ведущего нарушения, но и личностного, интеллектуального и психофизического развития в целом, от которых зависит прогноз интеграции такого обучающегося в социум. Актуальность изучения личностных особенностей детей, имеющих симптомы дисграфии и/или дислексии, обусловлена несколькими причинами: во-первых, это проблемы с дальнейшей социализацией ребенка; во-вторых - это непрерывно растущее количество детей в России и в мире с подобными нарушениями (Rello, 2014; O’Hare, 2010; Klim-Klimaszewska, Nazaruk, 2018; Заваденко, 2016).

Сложившаяся в образовании ситуация приводит современную дидактику к поиску новых технологий, которые соответствовали бы компетентностной парадигме образования и в то же охватывали детей с особыми образовательными потребностями в противовес знаньевому методу.

Ещё в 1970-х годах начался поиск образовательных систем, имеющих целью не просто передачу опыта и знаний, но способных создать такие условия, чтобы происходило «формирование такой картины мира в совместной деятельности со взрослыми и сверстниками, которая бы обеспечивала ориентацию личности в раздичного рода жизненных ситуациях, в том числе в ситуациях неопределённости»,- отмечал в своих работах выдающийся отечественный психолог А. Г. Асмолов (Асмолов, 2013, с. 9). Идея об образовании, наделенном смыслами, была высказана в работах А. Г. Асмолова, Б. С. Братусь, Е. В. Субботского, А. С. Цветковой и др. (Асмолов и др., 1979). Уже в середине 80-х годов сформировалась новая научная дисциплина - смыслодидактика: дидактика, обращённая к смысловым структурам дичности и представленная психологическим содержанием, преломленным через дидактическую структуру. На исследование смыслообразования в учебном процессе выводит сама догика развития психодогии и дидактики - подчёркивают учёные. Через уроки, способствующие смысловому развитию, можно отслеживать и описывать развитие ребёнка (Абакумова, Ермаков, Фоменко, 2013). В контексте смыслодидактической концепции развитие следует понимать как «смыслообразование», как «расширяющийся 
КОРРЕКЦИОННАЯ ПЕДАГОГИКА

смысл»,- отмечает Абакумова И. В., а смысловое развитие ребёнка является той глобальной целью, которая позволит ему выйти за пределы «актуального Я» к «Я потенциальному». «Абсодютной ценностью образования сегодня явдяется «ребёнок как человек, личность с её смысловой стержневой структурой, внутренним «Я»,- подчеркивает И. В. Абакумова (Абакумова, 2008, с. 102).

Особенности развития вызывают трансформации формирования смысловой сферы. Смыслодидактической школой Абакумовой И. В накоплен потенциал теоретических и эмпирических исследований, рассматривающих не только факторы, инициирующие смыслообразование в учебном процессе у здоровых подростков, юношей и девушек, но и раздичные видоизменения смысловых образований у детей с ограниченными возможностями развития, имеющими нулевой уровень смыслов: у неслышащих юношей и девушек, детей с коммуникативными расстройствами при нарушениях поведения аутистического спектра и гиперактивности. Однако недостаточность данных набдюдается в исследованиях особенностей развития смысловой сферы у младших шкодьников с речевыми расстройствами. В то время как именно расстройства речи, как психической деятельности, требующей подимодадьной мозговой организации и наиболее чувствительной к повреждающим воздействиям, широко представлены среди популяции младших школьников и ранжируются от лёгкой речевой недостаточности до тяжёдых расстройств языковой способности, препятствующих нормальному развитию коммуникативного поведения, овладению школьными навыками и социализации ребёнка. Нами получены данные, свидетельствующие об особенностях самоотношения у младших шкодьников с дисграфией, дислексией, которые способствуют проблемам социальной адаптации этих обущающихся (Мацюк, 2021). Расширяя границы исследования смысловой сферы младших школьников с дисграфией и дислексией, была предпринята попытка рассмотреть становление ценностных установок по отношению к семье как первичной малой группе. Это позволит, по нашему мнению, характеризовать особенности формирования группоцентраций как параметра развития смысловой сферы у категории младших школьников с речевыми расстройствами.

\section{Методы}

Эмпирического исследование, проведенное на базах МАОУ «Дицей № 27 им. А. В. Суворова» г. Ростова-на-Дону и МБОУ «Школа № 22» г. Ростова-наДону, было направлено на выявление особенностей ценностного отношения к семье у младших школьников с дисграфией и дислексией как фактора развития ценностно-смысловой сферы в младшем школьном возрасте.

Объектом сравнительного исследования являлись младшие школьники с нарушениями письма и чтения и их сверстники без расстройства школьных навыков в возрасте от 8 до 11 лет. Методику исследования составиди 2 
экспериментальные серии, направленные на подтверждение или опровержение гипотезы о влиянии дисграфии и дислексии на специфику ценностного отношения к семье как фактора развития ценностно- смысловой сферы в младшем школьном возрасте. Выборку составили 65 младших школьников (29 мальчиков и 36 девочек) в возрасте 8-11 лет.

Наблюдение за речью детей в учебной и внеучебной деятельности, предшествовавшее проведению экспериментальной части, и беседа с учителем начальных классов позводили сделать предварительные выводы о сформированности коммуникативного поведения, состоянии монологической и диалогической формы устной речи испытуемых.

В I серии эксперимента и была использована тестовая методика экспресс-диагностики письменной речи младших школьников Т. А. Фотековой, Т. В. Ахутиной (Фотекова, Ахутина, 2018). На основании обработки результатов тестирования, оценивались навыки языкового и звукового анализа, сформированность процессов письма и чтения.

Во II серии проводилась проективная методика «Рисунок семьи» (Бодалев, Стодин, Аванесов, 2006) направленная на диагностику внутрисемейных отношений. Исследовадись следующие характеристики междичностных отношений в семье: благоприятная семейная ситуация, тревожность, конфликтность в семье, чувство неполноценности и враждебность в семье.

\section{Резудьтаты}

Кодичественный анализ результатов методики I серии - теста Т. А. Фотековой, Т. В. Ахутиной (Фотекова, Ахутина, 2018) выявил у 37 \% детей дисграфические и дислексические расстройства.

По итогам проведения проективной методики «Рисунок семьи» во II серии эксперимента, обучающиеся были распределены на 3 группы: 1 группа - младшие школьники с дисграфией, дислексией, рисунки которых имели особенности 37 \% от общего количества участвующих в тесте; 2 группа-младшие школьники без речевых расстройств, но со специфическим выполнением теста - $29 \%$. У школьников третьей группы (34 \% обучающихся) не выявлено речевых расстройств, и интерпретация рисунков свидетельствовала о переживании детьми эмоционального благополучия в семье.

В группеобучающихся с дисграфией и дислексией максимальные показатели были зафиксированы по следующим характеристикам межличностных отношений: средний уровень тревожности - у 58 \% шкодьников, низкий - у 34 \%; конфликтность на высоком уровне у $12 \%$ учеников, на среднем уровне - у $55 \%$; $43 \%$ детей этой группы ощущают умеренно-выраженное, а $12 \%$ - острое чувство неполноценности в семье. Интересно распределились результаты по показатедям враждебность в семье и чувство неполноценности в семье: около половины 
КОРРЕКЦИОННАЯ ПЕДАГОГИКА

обучающихся этой группы испытывают умеренно-выраженную враждебность в семье (49\%), однако, практически столько же школьников с дисграфией (46\%) продемонстрировади низкий уровень этого показателя. Чувство неполноценности в семье ощущают 43 \% школьников этой группы, но 45 \% такого чувства не испытывают. Благополучие в семье, по результатам теста, ощущают $88 \%$ школьников. Первичные данные представлены в таблице 1.

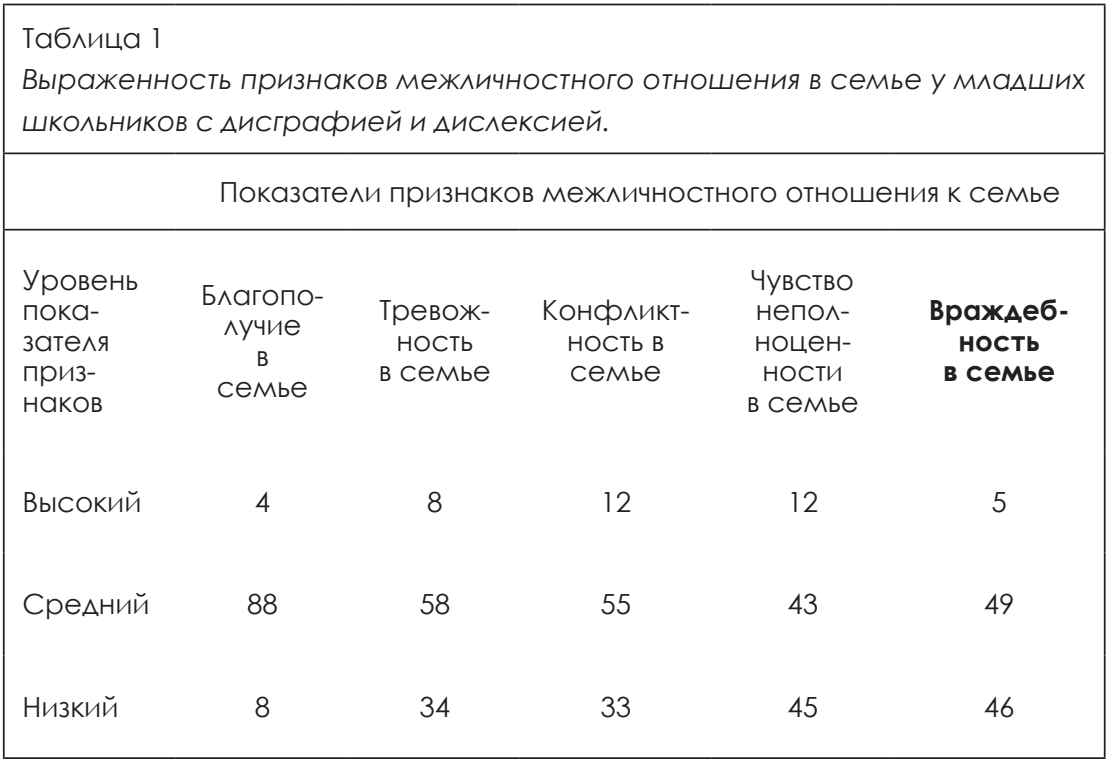

Иные выводы можно сделать о работах школьников, не имеющих нарушения письма и чтения. Аидирующие показатели группе обучающихся без расстройств школьных навыков, как и у школьников с дисграфией и дислексией, по критерию умеренно выраженная тревожность (64\%). При этом, обращает на себя внимание тот факт, что дети, проживающие в благополучной социальной среде и обучающиеся в математическом дицее, продемонстрировали значительный показатель умеренно-выраженной конфликтности (63\%). Существенные отличия в результатах тестирования двух групп наблюдаются по показателям «чувство неполноценности в семье» - средний уровень лишь у 31 \%, а 69 \% школьников не испытывают неполноценности, и «враждебность в семье», где средний уровень зафиксирован у $11 \%$, а 89 \% - не испытывают враждебности. Показатель благополучия в семья также высок, как и у школьников с дисграфией-умеренно-выраженный уровень благополучия в семье зафиксирован по итогам теста у 89 \% обучающихся. 


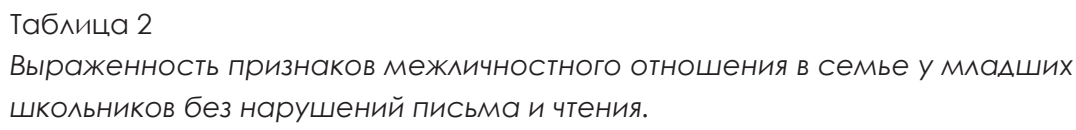

Показатели признаков межличностного отношения к семье (\%)

\begin{tabular}{|c|c|c|c|c|c|}
\hline Уровень & & & & & \\
\hline пока- & Б^агопо- & Тревож- & КОНФАИКт- & $\begin{array}{c}\text { Чувство } \\
\text { неполнонен- }\end{array}$ & Враждеб- \\
\hline зателя & лучие в & НОСТь & HOCTb B & HOCTИ & НОСТь \\
\hline $\begin{array}{l}\text { приз- } \\
\text { наков }\end{array}$ & семье & в семье & семье & в семье & в семье \\
\hline
\end{tabular}

$\begin{array}{lccccc}\text { Высокий } & 11 & 5 & 5 & & \\ \text { Средний } & 89 & 64 & 63 & 31 & 11 \\ \text { Низкий } & 0 & 31 & 32 & 69 & 89\end{array}$

Примечательно, что преобладание умеренно выраженной тревожности было зафиксировано у этих же обучающихся при исследовании особенностей самоотношения, посредством интерпретации резуяьтатов проективной методики «Автопортрет» в 2020 г. Тогда умеренно - выраженная тревожность была выявлена практически у половины школьников без расстройств школьных навыков (47\%), а в группе обучающихся с дисграфией и дислексией этот показатель отмечался у 59 \% детей (Мацюк, 2021).

Сравнительный анализ результатов теста показал, что в обеих группах фиксируется достаточно высокий показатель по среднему уровню тревожности и конфликтности. При этом, в обеих группах не оказалось детей, которые бы воспринимали атмосферу в семье как неблагополучную. Более того, выявлено практически идентичное совпадение в показателях восприятия подавляющим большинством детей уровня благополучия семьи как среднего. Существенные расхождения отмечаются по критериям «чувство неподноценности в семье» и «враждебность», где у благополучно обучающихся школьников выявлен невысокий уровень враждебности и неполноценности в семье, а у детей с дисграфией и дислексией эти показатели иные: более половины из них испытывают чувство враждебности в семье и почти половина детей группы-умеренно-выраженное чувство неполноценности в семье.

\section{Обсуждение результатов}

Давая оценку характеристикам основных параметров эмоционального отношения к семье у младших школьников с дисграфией, можно диагностировать 
КОРРЕКЦИОННАЯ ПЕДАГОГИКА

следующее: умеренно- выраженные показатели практически по всем характеристикам, свидетельствующим о неблагополучии (тревожность, конфликтность, чувство неполноценности, враждебность в семье) наблюдаются в среднем у половины группы школьников с нарушениями письма и чтения, при том, что эти же учащиеся в подавляющем бодьшинстве оценивают ситуацию в семье как благополучную. Следует отметить, что при проведённом нами исследовании особенностей самоотношения у этой же группы детей, посредством проективной методики «Автопортрет», были зафиксированы показатели, также свидетельствующие о надичии внутреннего конфликта: высокий уровень социальных притязаний в сочетании со страхами и тревожностыю, выраженная зависимость (в большей степени от матери) и защитная позиция в сочетании проявлениями компенсаторной агрессии. Это, по нашему мнению, связано с трудностями в стадиях созревания «Я» школьников с дисграфией и нарушением нормального механизма адаптации. Своеобразие процесса формирования устойчивой внутренней позиции у этой категории детей характеризуется задержкой в формировании системных новообразований психики младшего школьного возраста: мотивационных установок (Долгова, Зиборова, Петриченко, 2018) и самосознания. Отталкиваясь от выводов И. В. Абакумовой, о том, что становление способности к саморефлексии и есть смысловое развитие ребёнка, можно сделать закдючение о вдиянии задержки в формировании осознанности своего социального «Я» детьми младшего школьного возраста с нарушениями письма и чтения на процесс формирования группоцентраций и, прежде всего, ценностного отношения к семье как к первичной малой группе общества в целом.

Следуя за логикой процесса освоения младшими школьниками нравственных ценностей (Кильдюшова, Валеева, 2015) и учитывая психологические особенности младших школьников с нарушениями письма и чтения, полученные результаты можно интерпретировать как наличие ретардации процессуального аспекта освоения детьми нравственных ценностей: присваивая ценности семьи и продуцируя своё ценностное отношение к обществу, дети этой категории замедляются на этапе преобразования своего «Я» по отношению к родным, проектирования своей роли в жизни семьи и в конечном счёте в развитии от «актуального Я» к «Я потенциальному» как главного показателя смыслового развития ребёнка. Знания о семейных ценностях и умение их дифференцировать наталкиваются на трудности действенности ценностного отношения к семье, неумения оперировать понятиями не только в решении практических задач, но даже при воссоздании воображаемой ситуации.

Аидирующие показатели тревожности среди прочих характеристик объясняются, на наш взгляд, сочетанием внутриличностных факторов, таких как внутренний конфликт, и внешних (условия семейного воспитания, взаимодействия с учителем и сверстниками), что подчёркивала в своих исследованиях 
А. М. Прихожан (Прихожан, 2009). Одной из ведущих причин высокого уровня тревожности у школьников с дисграфией и дислексией, по нашему мнению, стоит считать указанную выше несформированность внутренней позиции школьника, препятствующую благоприятному эмоциональному фону и автономности от авторитетного взрослого (учителя), что подчеркивает в своих исследованиях Дубовский Д. В. (Дубовский, 2014). Школьники 8-10 лет с нарушениями письма и чтения, находятся в группе риска по развитию когнитивных дефицитов, поскольку учебная нагрузка, подкрепляемая ежедневным использованием цифровых устройств, вдияет непосредственно на неокрепшие психические процессы, провоцируя школьный стресс, сопряженные с ним нарушения эмоционально-личностного развития. Влияние учебной нагрузки на несозревшие психические процессы, внедрение в ежедневную жизнь цифровых устройств повышает риск развития когнитивных дефицитов у школьников этой группы, что подчеркивает в своих исследованиях Безруких М. М. (Безруких, 2009). Эти показатели тревожности в семье можно связать с результатами последних исследований, говорящих о сохраняющейся тенденция «педагогизации» взаимодействия родителей с ребёнком, ориентации дишь на его узкокогнитивное развитие, потери позиции безусловного принятия и лишение эмоциональной близости и поддержки (Горлова, Константинова, 2018).

Результаты исследования характеристик межличностного отношения в семье у младших школьников с дисграфией и дислексией и их сравнительный анализ с исследованием особенностей самоотношения у этой же группы детей приводят к выводу о неразрывной связи процесса овладения навыками письма и чтения не только с эмоционально-волевой сферой и особенностями самооценки, но и распространяются в дальнейшем на процессуальный аспект освоения детьми семейных ценностей, как этапом развития ценностно- смыловой сферы личности ребёнка, следующим за первоначальным формированием способности к саморефлексии. Влияние нарушений письма и чтения на процесс становления ценностного отношения к семье заслуживает дополнительного изучения и верификации.

\section{Выводы}

Подтвердилась гипотеза исследования о специфике становления ценностного отношения к семье у младших школьников с дисграфией и дислексией. Результаты проведения методики «Рисунок семьи» показали наличие умеренно-выраженной тревожности, конфликтности, чувства неполноценности и враждебности в семье.

Данные, полученные в результате выполнения методики «Рисунок семьи» обучающимися с дисграфией и дислексией, коррелируют с исследованиями причин возникновения тревожности, особенностей формирования внутренней 
КОРРЕКЦИОННАЯ ПЕДАГОГИКА

позиции школьника и возникновения внутреннего конфликта у детей младшего школьного возраста.

Достаточно высок процент детей (63\%), у которых при благополучных социальных условиях развития и отсутствии расстройства школьных навыков по результатам методики выявлена тревожность и конфдиктность в семье. Это свидетельствует о невротических реакциях, внутреннем конфликте.

Поскольку, выявленные нами особенности становления ценностно- смысловой сферы коррелируют с результатами выполнения теста по исследованию критериев самоотношения у детей с дисграфией и дислексией, можно предположить, что диапазон изменений в смысловой сфере у младших школьников с нарушениями письма и чтения значительно шире, чем было зафиксировано по результатам проективной методики «Рисунок семьи». Особенности смысловой сферы этой категории детей нуждаются в дальнейшем исследовании и верификации.

Расширяя границы исследования смысловой сферы младших школьников с дисграфией и дислексией, целесообразно осуществить изучение социальной приспособленности и взаимоотношений с окружающими (сверстниками, учителями) для дальнейшего исследования сферы междичностных отношений.

Анализ и систематизация результатов исследования самоотношения и отношения к окружающим (сверстникам, близким родственникам, учителям) у младших школьников с дисграфией и дислексией позволит дать характеристики особенностям смысловой сферы этой категории обучающихся и составить практические рекомендации по гармонизации развития и оптимизации обучения этой категории школьников.

Автор заявляет об отсутствии конфликтов интересов.

\section{Литература}

Абакумова, И. В. (2008). Смыслодидактика: учебное пособие для магистрантов отделений педагогики и психологии. Ростов-на-Дону: Изд-во ЮФУ.

Абакумова, И. В., Ермаков, П. Н., Косикова, А. В. (2016). Смысловая сфера подростков: особенности развития в условиях включенного обучения. М.: КРЕДО.

Абакумова, И. В., Ермаков, П. Н., Фоменко, В. Т. (2013). Новодидактика. Книга 4. М.: КРЕДО.

Асмолов, А. Г. (2013). Вариативное образование в изменяющемся мире: социокультурная перспектива (тезисы о том, какой быть начальной школе). Образование и наука, 8(107), 3-13.

Асмолов, А. Г., Братусь, Б. С., Зейгарник, Б. В., Петровский, В. А., Субботский, Е. В., Хараш, А. У., Цветкова, А. С. (1979). О некоторых перспективах исследования смысловых образований дичности. Вопросы психологии, 4, 35-47.

Безруких, М. М. (2009). Трудности обучения в начальной школе: причины, диагностика, комплексная помощь. М.: Эксмо. 
Бодалев, А. А., Столин, В. В., Аванесов, В. С. (2000). Общая психодиагностика. СПб.: Изд-во «Речь».

Братусь, Б. С. (1999). Смысловая вертикаль сознания дичности. Вопросы философии, 1, 81-89.

Горлова, Е. Н., Константинова, В. Ю. (2018). Родительское отношение к детям с разным уровнем тревожности, обучающимся в первом классе. В Психологичекие проблемы современной семьи. Сборник материалов VIII международной научно-практической конференциии (С. 879-885). Екатеринбург: Уральский государственный педагогический университет.

Грязнов, С. А. (2020). Пути формирования семейных ценностей у младших шкодьников. Педагогические и социальные вопросы образования, 8, 150-159.

Долгова, О. И., Зиборова, Е. В., Петриченко, С. И. (2018). Способы формирования стойкой мотивации на групповых занятиях в системе комплексной нейрореабилитации у детей с раздичными формами дисграфии, дислексии в рамках интенсивного курса. В Чтение в циифровую эпоху: Сборник материалов VIII Международной научно-практической конференции Российской ассоциацุии дислексии (С. 103-108). М.: Государственный институт русского языка им. А. С. Пушкина.

Ефимова, О. Е., Левых, Н. Н. (2020). Формирование представлений о семейных ценностях у младших школьников. Научно-методический журнал «Поиск», 4(72), 38-40.

Заваденко, Н. Н. (2016). Школьная дезаптация в нейропедиатрической практике. Практика педиатра, 3, 60-70.

Кильдюшова, П. Е., Валеева, Р. А. (2015). К вопросу о формировании у младших школьников ценностного отношения к семье. Современные проблемы науки и образования, 3, 282-288.

Аубовский, Д. В. (2014). Феноменология и динамика развития внутренней позиции современных младших школьников. Психологическая наука и образование, 2, 50-67.

Мацюк, Е. А. (2021). Особенности принятия себя у младших школьников с нарушениями письма и чтения в условиях цифровизации образования. Мир науки. Педагогика и психология, 9(2), 16.

Мурзина, Ю. С. (2018). Представления молодежи о семейных ценностях. В Психологические проблемь современной семьи: сборник материалов VIII Международной научно-практической конференции (С. 530-538). Екатеринбург: Уральский государственный педагогический университет.

Прихожан, А. М. (2009). Психология тревожности: дошкольный и школьный возраст. 2 -е изд. СПб.: Питер.

Фактор, А. М., Камолов, С. Г., Никандрова, А. А. (2018). Человеческие ценности в цифровую эпоху. Моделирование, оптимизация и информационные технологии, 6-2(21), 83-103. 
КОРРЕКЦИОННАЯ ПЕДАГОГИКА

Фотекова, Т. А., Ахутина, Т. В. (2018). Диагностика речевых нарущений щкольников: практическое пособие. 3-е изд., испр. и доп. М.: Юрайт.

Чиркина, Г. В. (2012). Проблема обучения детей с нарушениями речи в контексте их особых образовательных потребностей. Учёные записки, 2, 155-166.

Щуркова, Н. Е. (2002). Педагогическая технология. М.: Педагогическое общество России.

Ядов, В. А. (2013). Саморегуляциия и прогнозирование социильного поведения личности: Диспозиционная концепция. 2-е расширенное изд. М.: Центр Социального Прогнозирования и Маркетинга.

Inglehart, R. F. (2018). Cultural Evolution. Peoples motivations are changing and reshaping the world. Cambridge: Cambridge University Press.

Klim-Klimaszewska, A., Nazaruk, S. (2018). Early assessment of the risk of dyslexia and dysgraphia among children aged 5-6 in the aspect of educational and therapeutic work of kindergartens. In Society. Integration. Education. Proceedings of the International Scientific Conference (pp. 558-573). Rezekne: Rēzeknes Tehnologiju Akadēmija.

Kuznetcova, E. A., Akhmetzyanova, A. I., Nigmatullina, I. A., Kurbanova, A. T. (2017). Prognostic competence as a factor of successful socialization of children with deficiency of development: statement of the problem. The Turkish Online Journal of Design, Art and Communication, 7, 1128-1133.

O'Hare, A. (2010). Dyslexia: what do paediatricians need to know? Occasional Review, 20(7), 338-343. doi: https://www.doi.org/10.1016/j.paed.2010.04.004

Rello, L. (2014). Design of Word Exercises for Children with Dyslexia. Procedia Computer Science, 27, 74-83. doi: https://www.doi.org/10.1016/j.procs.2014.02.010

\section{References}

Abakumova, I. V. (2008). Meaning didactics: textbook for masters of the departments of pedagogy and psychology. Rostov-on-Don: Publishing House of the South Federal University. (in Russ.).

Abakumova, I. V., Ermakov, P. N., Fomenko, V. T. (2013). Novodidactics. The Book 4. Moscow: CREDO. (in Russ.).

Abakumova, I. V., Ermakov, P. N., Kosikova, L. V. (2016). The meaning sphere of adolescents: features of development in the conditions of inclusive learning. Moscow: CREDO. (in Russ.).

Asmolov, A. G. (2013). Variable education in a changing world: a socio-cultural perspective (theses on what an elementary school should be like). Education and Science, 8(107), 3-13. (in Russ.).

Asmolov, A. G., Bratus', B. S., Zejgarnik, B. V., Petrovskij, V. A., Subbotskij, E. V., Harash, A. U., Cvetkova, L. S. (1979). On some perspectives of research of meaning formations of personality. Psychology issues, 4, 35-47. (in Russ.). 
Bezrukih, M. M. (2009). Learning difficulties in primary school: causes, diagnosis, comprehensive assistance. Moscow: Eksmo. (in Russ.).

Bodalev, A. A., Stolin, V. V., Avanesov, V. S. (2000). General psychodiagnostics. St. Petersburg: Publishing House "Rech". (in Russ.).

Bratus', B. S. (1999). The meaning vertical of personality consciousness. Philosophy Issues, 1, 81-89. (in Russ.).

Chirkina, G. V. (2012). The problem of teaching children with speech disorders in the context of their special educational needs. Lecture notes, 2, 155-166. (in Russ.).

Dolgova, O. I., Ziborova, E. V., Petrichenko, S. I. (2018). Methods for the formation of persistent motivation in group lessons in the system of complex neurorehabilitation in children with various forms of dysgraphia, dyslexia within the intensive course. In Reading in the digital age: proceedings of the VIII International Scientific and Practical Conference of the Russian Association for Dyslexia (pp. 103-108). Moscow: Pushkin State Russian Language Institute. (in Russ.).

Efimova, O. E., Levyh, N. N. (2020). Formation of ideas about family values among younger students. Scientific and methodical journal «Poisk», 4(72), 38-40. (in Russ.).

Faktor, A. M., Kamolov, S. G., Nikandrova, A. A. (2018). Human values in the digital age. Modeling, optimization and information technology, 6-2(21), 83-103. (in Russ.).

Fotekova, T. A., Ahutina, T. V. (2018). Diagnosis of speech disorders in schoolchildren: a practical guide. 3rd ed., rev. and add. Moscow: Yurayt. (in Russ.).

Gorlova, E. N., Konstantinova, V. Yu. (2018). Parental attitude towards children with different levels of anxiety studying in the first grade. In Psychological problems of the modern family. Proceedings of the VIII International Scientific and Practical Conference (pp. 879-885). Ekaterinburg: Ural State Pedagogical University. (in Russ.).

Gryaznov, S. A. (2020). Ways of forming family values in younger students. Pedagogical and Social Issues of Education, 8, 150-159. (in Russ.).

Inglehart, R. F. (2018). Cultural Evolution. Peoples motivations are changing and reshaping the world. Cambridge: Cambridge University Press.

Kildyushova, P. E., Valeeva, R. A. (2015). On the question of the formation of a value attitude towards the family in primary schoolchildren. Modern problems of science and education, 3, 282-288. (in Russ.).

Klim-Klimaszewska, A., Nazaruk, S. (2018). Early assessment of the risk of dyslexia and dysgraphia among children aged 5-6 in the aspect of educational and therapeutic work of kindergartens. In Society. Integration. Education. Proceedings of the International Scientific Conference (pp. 558-573). Rezekne: Rēzeknes Tehnologiju Akadēmija.

Kuznetcova, E. A., Akhmetzyanova, A. I., Nigmatullina, I. A., Kurbanova, A. T. (2017). Prognostic competence as a factor of successful socialization of children with deficiency of development: statement of the problem. The Turkish Online Journal of Design, Art and Communication, 7, 1128-1133. 
КОРРЕКЩИОННАЯ ПЕДАГОГИКА

Lubovsky, D. V. (2014). Phenomenology and dynamics of the development of the internal position of modern primary schoolchildren. Psychological Science and Education, 2, 50-67. (in Russ.).

Matsyuk, E. A. (2021). Features of self-acceptance among primary schoolchildren with writing and reading disorders in the context of digitalization of education. The World of Science. Pedagogy and Psychology, 9(2), 16. (in Russ.).

Murzina, Yu. S. (2018). Young people's ideas about family values. In Psychological problems of the modern family: proceedings of the VIII International Scientific and Practical Conference (pp. 530-538). Ekaterinburg: Ural State Pedagogical University. (in Russ.).

O'Hare, A. (2010). Dyslexia: what do paediatricians need to know? Occasional Review, 20(7), 338-343. doi: https://www.doi.org/10.1016/j.paed.2010.04.004

Prihozhan, A. M. (2009). Psychology of anxiety: pre-school and school age. 2nd ed. St. Petersburg: Piter. (in Russ.).

Rello, L. (2014). Design of Word Exercises for Children with Dyslexia. Procedia Computer Science, 27, 74-83. doi: https://www.doi.org/10.1016/j.procs.2014.02.010

Shhurkova, N. E. (2002). Pedagogical technology. Moscow: Pedagogical Society of Russia. (in Russ.).

Yadov, V. A. (2013). Self-regulation and prediction of social behavior of a person: a dispositional concept. 2nd extended ed. Moscow: The Center for Social Forecasting and Marketing. (in Russ.).

Zavadenko, N. N. (2016). School deaptation in neuropediatric practice. Pediatrician practice, 3, 60-70. (in Russ.). 